(c) American Dairy Science Association, 2004.

\title{
Management Practices and Reported Antimicrobial Usage on Conventional and Organic Dairy Farms ${ }^{1}$
}

\author{
A. G. Zwald, ${ }^{1}$ P. L. Ruegg, ${ }^{1}$ J. B. Kaneene,${ }^{2}$ L. D. Warnick, ${ }^{3}$ \\ S. J. Wells, ${ }^{4}$ C. Fossler, ${ }^{4}$ and L. W. Halbert ${ }^{2}$ \\ ${ }^{1}$ Department of Dairy Science \\ University of Wisconsin \\ Madison 53706 \\ ${ }^{2}$ Population Medicine Center \\ College of Veterinary Medicine \\ Michigan State University \\ East Lansing 48824 \\ ${ }^{3}$ Department of Population Medicine and Diagnostic Sciences \\ College of Veterinary Medicine \\ Cornell University \\ Ithaca, NY 14850 \\ ${ }^{4}$ Department of Clinical and Population Science \\ College of Veterinary Medicine \\ University of Minnesota \\ St. Paul 55108
}

\begin{abstract}
The primary objective was to compare reported antimicrobial usage between conventional and organic dairy farms. A secondary objective was to contrast selected management characteristics of conventional and organic dairy herds. A questionnaire was administered on site to selected dairy farmers located in Michigan, Minnesota, New York, and Wisconsin. Organic herds $(\mathrm{n}=32)$ were smaller and produced less milk than conventional herds $(n=99)$. Lactating cows in organic dairies were more likely to be housed in tie stalls, whereas most conventional dairies housed cows in free stalls and milked in a parlor. Total mixed rations and purchased feeds were used on more conventional dairy farms compared with organic dairy farms. Conventional dairy producers were more likely to use advice from veterinarians for recommendations of treatment, and organic dairy producers were more likely to rely on advice from other farmers. Based on recall of antibiotic usage in the previous $60 \mathrm{~d}, 5.1,84.9,9.1$, and $0.9 \%$ of farmers with conventional herds reported treatment of none, 1 to $10 \%, 11$ to $25 \%$, and $>25 \%$ of milk cows, respectively. Most organic farmers $(90.6 \%)$ reported no antibiotic treatments of milk cows, whereas $9.4 \%$ reported treating 1 to $10 \%$ of milk cows. Ceftiofur was the most commonly reported antibiotic for both farm
\end{abstract}

Received April 3, 2003.

Accepted July 16, 2003.

Corresponding author: P. L. Ruegg; e-mail: plruegg@wisc.edu.

${ }^{1}$ Supported by UDSA-NRI Program on Epidemiological Approaches to Food Safety. types. Milk replacer containing antibiotics was reportedly used on $49.5 \%$ of conventional herds but only on one organic herd $(3.1 \%)$. Antibiotics were used in heifer calves on $74.7 \%$ of conventional herds versus $21.9 \%$ of organic herds. Antibiotics to treat mastitis were used on 79.8\% of conventional herds but on none of the organic herds. Most organic farms were in compliance with standards in advance of implementation of regulations. (Key words: antibiotics, antimicrobials, organic, management)

Abbreviation key: $\mathbf{C O N}=$ conventional, $\mathbf{O R G}=$ organic.

\section{INTRODUCTION}

Antibiotic treatment of dairy cows for infectious diseases is a relatively common and necessary occurrence (McEwen et al., 1991). The overall availability and use of antimicrobials have been estimated in a US population-based survey (National Animal Health Monitoring System, 1997); however, there are few data available on the use of individual antimicrobials. It is difficult to measure antimicrobial usage on farms because of the difficulty of obtaining an accurate assessment of dosage and duration of treatment. Antibiotics are administered to animals through injections (e.g., intramuscular, intravenous, or subcutaneous), orally, topically, or via intramammary or intrauterine infusion. A survey of US veterinarians found that the drugs most often used or prescribed were antibiotics, followed by antiinflammatories and tranquilizers or analgesics (Sundlof et al., 1995). 
Several types of antimicrobials are commonly used in food animals (Mitchell et al., 1998). Antimicrobial classes include beta-lactams (e.g., penicillin, ampicillin, and cephalosporin), tetracyclines (e.g., oxytetracycline, tetracycline, and chlortetracycline), aminoglycosides (e.g., streptomycin, neomycin, and gentamycin), macrolides (e.g., erythromycin), lincosamides (e.g. lincomycin and pirlimycin), and sulfonamides (e.g., sulfamethazine and others) (Mitchell et al., 1998; Hoeben et al., 1998). A survey of US veterinarians reported that antibiotics were the drugs most often used to treat lactating dairy cows; the most common reason for treatment was mastitis therapy (Mitchell et al., 1998).

The use of antimicrobials in agriculture is not universally accepted, and the market for organic agricultural products has increased. Although the organic market has been growing at 20 to $30 \%$ per year in the United States, scientific literature concerning organic dairy farming is relatively rare (Green, 2000). As of October 2002, the National Organic Program, under the Agricultural Marketing Service and USDA, defined standards for organic production and handling. The national organic standards address the methods, practices, and substances used in producing and handling crops, livestock, and processed agricultural products. The requirements apply to the production process, not to measurable properties of the product itself. It is a requirement that livestock destined for slaughter are raised under organic management from the last third of gestation. During transition to organic status, cattle intended for dairy production do not need to be managed organically until a year before commencing lactation. After attaining organic status, all animals on the dairy must be raised under organic rules from the last third of gestation. Animals sold as organic may not have received hormones to promote growth, or antibiotics for any reason. Preventive management practices, including vaccines, are allowed. Producers are prohibited from withholding treatment from a sick or injured animal; however, products derived from animals treated with a prohibited medication may not be sold as organic. All organically raised cattle must have access to the outdoors. The current national organic standards were implemented after this study ended. There are no studies contrasting the use of antimicrobials based on specific farming systems (organic vs. conventional). The primary objective of this study was to compare reported antimicrobial usage between conventional and organic dairy herds. A secondary objective was to contrast selected management characteristics of the conventional and organic dairy herds enrolled in this study.

\section{MATERIALS AND METHODS}

\section{Recruitment and Herd Selection}

Study farms $(n=131)$ were recruited from dairy herds located in the states of Michigan, Minnesota, New York, and Wisconsin between May 2000 and March 2001. Recruitment methods differed slightly among states and between farm types [conventional (CON) and organic (ORG)]. Conventional herds were identified by obtaining a list of dairy farms licensed to ship milk from the department of agriculture of each respective state. Organic herds were required to be certified by an organic certifying agency for at least $3 \mathrm{yr}$. There is no central database of ORG herds, so lists of ORG farms were obtained through personal contacts, organic milk cooperatives, and independent organic certifying organizations. In some states, all known ORG herds within each state were contacted by phone to determine eligibility and interest in participation in this study. In Minnesota and Wisconsin, letters were sent to ORG herds to solicit participation in this study.

Conventional herds were contacted by letters $(500$ to 571 per state for a total of 2102 letters) mailed to randomly selected herds located in counties near each university. Nonresponders received multiple mailings in order to increase participation rate. The letters included a postage paid return postcard. Farms that indicated willingness to participate in the study $(n=295)$ were screened to ensure that they met predefined criteria for eligibility: preweaned calves and heifers raised on the farm property, a herd record system, unique identification for all cows and calves, $>90 \%$ of the herd population was Holstein, the farm shipped milk year round, and the farm owner agreed to participate in the study. The absence of any single eligibility criterion resulted in exclusion from the study. The four herd size categories of 30 to 49 cows $(n=21), 50$ to 99 cows ( $n=$ $42), 100$ to 199 cows $(\mathrm{n}=33)$, and 200 or more cows $(\mathrm{n}=$ 35 ) were filled by random selection from eligible herds.

\section{Questionnaire}

A 64-question survey instrument (available on request) including inventory and herd size (3 questions), herd expansion status (2 questions), housing (5 questions), feed and water system (10 questions), calf management and feeding (12 questions), production and health (10 questions), manure management (9 questions), and antimicrobial use (13 questions) was administered. The questionnaire was adapted from a previously published survey (National Animal Health Monitoring System, 1997). For many questions, producers could select all options that applied specifically to their farms. An individual animal area was defined as an area where animals could not commingle with other dairy animals. A multiple animal area was defined as an area where animals did have opportunities for direct contact with other dairy animals. Diets of dry cows were recorded separately from diets fed to lactating cows. An 
additional 10 questions (addressing the separation and sale of animals that received antimicrobials and type of products used for treatments) were included on the questionnaire administered to ORG dairy farms. To reduce recall bias, all questions referred to practices used in the previous $60 \mathrm{~d}$ (unless otherwise noted). For one question, we asked study participants to estimate the percentage of cattle that had received at least one antibiotic injection or oral dose of antibiotics within the previous $60 \mathrm{~d}$ for adult cows (milking or dry), bred heifers, and heifer calves (preweaned or weaned). This question did not include the use of intramammary products or topical administration of antibiotics but did include injectable and oral treatments given by farm workers or veterinarians. A separate question addressed the use of intramammary dry cow therapy. The questionnaire was pretested by administration to several farmers and 2 faculty members located in Minnesota. The questionnaire took approximately $45 \mathrm{~min}$ to $2 \mathrm{~h}$ to complete and was administered during a farm visit. Data were collected during a meeting with the farmer or herdsperson and included an interview, review of product labels (i.e., milk replacer and antibiotics), and information obtained during a farm tour.

\section{Statistical Analyses}

Data from all states were entered into a central database for analysis. Data were stratified by herd size $(\leq 120$ total cattle $=$ small, $>120$ total cattle $=$ large $)$ for initial data analysis. There was no significant difference in the number of cows between ORG and CON herds for small herds (89.9 cows [CON], 84.0 cows [ORG]; $P=0.41$ ). Large CON herds contained more cattle compared with large ORG herds (398.0 cows [CON], 262.9 cows [ORG]; $P=0.02$ ). The data were stratified by herd size (small or large) with herd type (ORG or CON) forming the rows and the response variable (yes or no for specified antibiotics) forming the columns and were analyzed using the Cochran-MantelHaenszel option in PROC FREQ (SAS, 1999). Herd size was not associated with antibiotic usage so data were combined for further analysis. The PROC FREQ chisquare analysis and Fisher's exact test (SAS, 1999) were used to identify associations between herd type and the use of selected antibiotics or other treatments. Continuous variables were analyzed using PROC TTEST and PROC MEANS (SAS, 1999).

\section{RESULTS}

\section{Herd Characteristics}

Herd enrollment was distributed among the participating states: $30(\mathrm{CON})$ and $2(\mathrm{ORG}) ; 23(\mathrm{CON})$ and 10
(ORG); $25(\mathrm{CON})$ and 9 (ORG); and $21(\mathrm{CON})$ and 11 (ORG) for Michigan, Minnesota, New York, and Wisconsin, respectively. The distribution of enrollment by herd type was: 12 (ORG) and $9(\mathrm{CON}) ; 12(\mathrm{ORG})$ and 30 (CON); 4 (ORG) and $29(\mathrm{CON})$; and 4 (ORG) and 31 (CON) for herd size categories of 30 to 49, 50 to 99, 100 to 199 , and $>200$ total cows, respectively.

Organic herds were smaller and produced less milk than CON herds (Table 1). One ORG herd was allowed to remain in the study even though it contained only 26 adult dairy cows on the day of the herd visit. Higher SCC values were reported for proportionally more ORG herds compared with SCC values reported by CON herds (Table 1). A larger proportion of cows in CON herds were milked in a pit parlor, whereas a larger proportion of cows in ORG herds were milked in a tie stall or stanchion barn (Table 1).

\section{Housing and Management}

Preweaned calves in ORG herds were housed in areas that permitted less contact with other animals, but there was no significant association between herd type and specific housing types such as the housing of preweaned calves nor with the housing of weaned calves (Table 2). However, significantly more CON herds housed lactating cows in free stalls and had maternity housing separate from lactating cows compared with ORG herds (Table 2). Calves in more CON herds were fed individually (i.e., no access to group feeding such as shared troughs) compared with ORG herds. The use of separate facilities to house sick animals separately from lactating cows and the washing of calf pens were not influenced by herd type.

Nutritional management was affected by herd type. A significantly greater percentage of CON herds fed lactating cows a TMR $(79.8$ vs. $31.3 \%, P<0.001)$, a transition ration ( 71.7 vs. $31.3 \%, P<0.001$ ), and anionic salts (33.3 vs. $3.1 \%, P=0.001)$ to close-up cows. Whole soybeans and soybean meal were the only purchased feeds reported on ORG dairies, but significantly less ORG (46.9\%) compared with CON (90.9\%) herds used them $(P<0.001)$. The use of whole cottonseed or hulls, brewer's byproducts, and tallow or animal fat was not reported for ORG dairies, whereas these products were used on $50.5,48.5$, and $60.6 \%$ of CON farms, respectively $(P<0.001)$. No organic farmers reported the use of meat and bone meal or blood meal, whereas these products were used on $27.3 \%$ of $\mathrm{CON}$ herds $(P<0.02)$.

Individual automatic water bowls were used on significantly more ORG herds (Table 3). Occasional use of surface water by milking cows and primary use of surface water by dry cows occurred in significantly more ORG herds (Table 3). Chlorinated drinking water was 
Table 1. Selected descriptive statistics for herds by herd type.

\begin{tabular}{|c|c|c|c|c|c|c|c|c|c|c|}
\hline & \multicolumn{5}{|c|}{ Conventional } & \multicolumn{5}{|c|}{ Organic } \\
\hline & $\mathrm{N}$ & Mean & $\mathrm{SE}$ & Min & $\operatorname{Max}$ & $\mathrm{N}$ & Mean & $\mathrm{SE}$ & Min & $\operatorname{Max}$ \\
\hline Total adult cows ${ }^{1}$ & 99 & $192.2^{\mathrm{a}}$ & 17.3 & 30.0 & 875.0 & 32 & $90.5^{\mathrm{b}}$ & 16.8 & 26.0 & 368.0 \\
\hline Total cattle ${ }^{2}$ & 99 & $348.2^{\mathrm{a}}$ & 30.0 & 50.0 & 1693.0 & 32 & $173.4^{\mathrm{b}}$ & 28.2 & 47.0 & 677.0 \\
\hline Rolling herd average (kg) & 87 & $9896.9^{\mathrm{a}}$ & 142.9 & 6905.9 & $13,063.5$ & 22 & $7555.9^{\mathrm{b}}$ & 235.7 & 5443.1 & 9911.0 \\
\hline Daily milk yield per cow (kg) & 28 & $30.9^{\mathrm{a}}$ & 1.1 & 20.4 & 39.0 & 14 & $22.8^{\mathrm{b}}$ & 1.2 & 13.6 & 30.8 \\
\hline $\mathrm{SCC}^{3}$ & & & & & & & & & & \\
\hline (cells per ml) & & $(\%)$ & & & & & $(\%)$ & & & \\
\hline$<100,000$ & 1 & $(1.0)$ & & & & 1 & $(3.1)$ & & & \\
\hline $100,000-199,999$ & 30 & $(30.3)$ & & & & 2 & $(6.3)$ & & & \\
\hline $200,000-299,999$ & 42 & $(42.4)$ & & & & 14 & $(43.8)$ & & & \\
\hline $300,000-399,999$ & 18 & (18.2) & & & & 10 & $(31.3)$ & & & \\
\hline $400,000-499,999$ & 6 & $(6.1)$ & & & & 5 & $(15.6)$ & & & \\
\hline$\geq 500,000$ & 2 & $2.0)$ & & & & 0 & $(0.0)$ & & & \\
\hline \multicolumn{11}{|l|}{ Milking facility ${ }^{4}$} \\
\hline Pit parlor & 60 & $(60.6)$ & & & & 6 & $(18.8)$ & & & \\
\hline Flat parlor & 7 & $(7.1)$ & & & & 0 & $(0.0)$ & & & \\
\hline Tie stall or stanchion & 32 & $(32.3)$ & & & & 26 & $(81.3)$ & & & \\
\hline
\end{tabular}

${ }^{\mathrm{a}, \mathrm{b}}$ Means within the same row with different superscripts differ significantly, $P<0.002$.

${ }^{1}$ Includes lactating and dry cows.

${ }^{2}$ Includes adults and youngstock.

${ }^{3} \mathrm{SCC}$ category was associated with herd type, $P=0.04$.

${ }^{4}$ Type of milking facility was associated with herd type, $P<0.001$.

Table 2. Cattle housing for conventional $(n=99)$ and organic $(n=32)$ dairy herds.

\begin{tabular}{|c|c|c|c|c|c|}
\hline & \multicolumn{2}{|c|}{ Conventional } & \multicolumn{2}{|c|}{ Organic } & \multirow[b]{2}{*}{$P^{1}$} \\
\hline & $\begin{array}{l}\text { Number of } \\
\text { herds }\end{array}$ & $(\%)$ & $\begin{array}{l}\text { Number of } \\
\text { herds }\end{array}$ & $(\%)$ & \\
\hline \multicolumn{6}{|l|}{ Housing of preweaned calves ${ }^{3}$} \\
\hline Hutch & 56 & $(56.6)$ & 13 & $(40.6)$ & $\mathrm{NS}^{2}$ \\
\hline Tie stall & 2 & $(2.0)$ & 2 & $(6.3)$ & NS \\
\hline Tied in stanchion barn & 10 & (10.1) & 4 & (12.5) & NS \\
\hline No contact with other animals & 13 & (13.1) & 20 & $(62.5)$ & $<0.001$ \\
\hline Contact with other animals possible & 43 & $(43.4)$ & 9 & $(28.1)$ & 0.12 \\
\hline \multicolumn{6}{|l|}{ Housing of weaned calves ${ }^{3}$} \\
\hline Hutch & 4 & (4.0) & 0 & $(0.0)$ & NS \\
\hline Free stall & 22 & $(22.2)$ & 7 & (21.9) & NS \\
\hline Tie stall & 6 & $(6.1)$ & 3 & $(9.4)$ & NS \\
\hline Contact with other animals possible & 89 & $(89.9)$ & 30 & (93.8) & NS \\
\hline \multicolumn{6}{|l|}{ Housing of lactating cows ${ }^{3}$} \\
\hline Free stall & 73 & $(73.7)$ & 11 & $(34.4)$ & $<0.001$ \\
\hline Tie stall & 35 & $(35.4)$ & 25 & (78.1) & $<0.001$ \\
\hline Contact with other animals possible & 14 & (14.1) & 11 & $(34.4)$ & 0.011 \\
\hline \multicolumn{6}{|l|}{ Maternity housing ${ }^{3}$} \\
\hline Free stalls & 6 & (6.1) & 2 & (6.3) & NS \\
\hline Tie stalls & 8 & $(8.1)$ & 9 & $(28.1)$ & $<0.01$ \\
\hline No contact with other animals & 43 & $(43.4)$ & 16 & $(50.0)$ & NS \\
\hline Contact with other animals possible & 58 & $(58.6)$ & 13 & $(40.6)$ & 0.08 \\
\hline Separate from lactating cows & 82 & $(82.8)$ & 16 & $(50.0)$ & $<0.001$ \\
\hline Sick cows housed separate from lactating cows & 41 & (41.4) & 10 & $(31.3)$ & NS \\
\hline Preweaned calves fed on an individual basis & 92 & $(92.9)$ & 25 & (78.1) & $<0.05$ \\
\hline Calf pens washed on a regular basis & 51 & $(51.5)$ & 17 & $(53.1)$ & NS \\
\hline No calf pens or hutches used to house calves & 11 & (11.1) & 10 & $(31.3)$ & $<0.05$ \\
\hline
\end{tabular}

${ }^{1}$ Contrast between conventional and organic.

${ }^{2} \mathrm{NS}=\mathrm{P}>0.15$.

${ }^{3}$ Column totals within herd type can exceed number of enrolled herds because housing options were not exclusive choices. 
Table 3. Water sources by herd type for conventional $(n=99)$ and organic $(n=32)$ dairy herds.

\begin{tabular}{|c|c|c|c|c|c|}
\hline & \multicolumn{2}{|c|}{ Conventional } & \multicolumn{2}{|c|}{ Organic } & \multirow[b]{2}{*}{$P$} \\
\hline & $\begin{array}{l}\text { Number of } \\
\text { herds }\end{array}$ & $(\%)$ & $\begin{array}{l}\text { Number of } \\
\text { herds }\end{array}$ & $(\%)$ & \\
\hline \multicolumn{6}{|l|}{ Milking cows ${ }^{1}$} \\
\hline Individual automatic water bowl & 36 & $(36.4)$ & 26 & $(81.3)$ & $<0.001$ \\
\hline Automatic water bowl shared by group & 37 & $(37.4)$ & 13 & $(40.6)$ & $\mathrm{NS}^{2}$ \\
\hline Water tank for multiple cows & 83 & $(83.8)$ & 26 & $(81.3)$ & NS \\
\hline Occasional access to surface water & 10 & $(10.1)$ & 10 & $(31.3)$ & $<0.01$ \\
\hline Main water source is surface water & 3 & (3.0) & 3 & $(9.4)$ & 0.14 \\
\hline \multicolumn{6}{|l|}{ Dry cows ${ }^{1}$} \\
\hline Individual automatic water bowl & 21 & $(21.2)$ & 15 & (46.9) & $<0.01$ \\
\hline Automatic water bowl shared by group & 47 & $(47.5)$ & 17 & $(53.1)$ & NS \\
\hline Water tank for multiple cows & 61 & $(61.6)$ & 19 & $(59.4)$ & NS \\
\hline Occasional access to surface water & 14 & (14.1) & 8 & $(25.0)$ & 0.15 \\
\hline Main water source is surface water & 9 & (9.1) & 7 & (21.9) & 0.06 \\
\hline \multicolumn{6}{|l|}{ Source of drinking water ${ }^{1}$} \\
\hline Well & 96 & $(97.0)$ & 32 & $(100.0)$ & NS \\
\hline Municipal water & 1 & $(1.0)$ & 0 & $(0.0)$ & NS \\
\hline Surface water & 24 & $(24.3)$ & 9 & $(28.1)$ & NS \\
\hline Drinking water for cows chlorinated & 13 & (13.1) & 0 & $(0.0)$ & $<0.05$ \\
\hline
\end{tabular}

${ }^{1}$ Column totals within herd type can exceed number of enrolled herds because options were not exclusive choices.

${ }^{2} \mathrm{NS}=\mathrm{P}>0.15$.

used on significantly more CON dairies. There was no significant association of herd type with group access to individual automatic water bowls, the use of water tanks for multiple cows, occasional use of surface water by dry cows, and use of surface water as main water sources for milking cows. Similarly, there was no significant association between water source (well water, municipal source, or surface water) and herd type.

Physical contact between poultry and dairy cattle was reported on significantly more ORG herds $(37.5 \%)$ compared with CON herds $(11.1 \% ; P=0.001)$. Herd type was not associated with physical contact with beef cattle, horses, pigs, sheep, goats, dogs, cats, or wild geese $(P>0.20)$.

A treated cow was defined as a cow that had received antibiotics that required a withholding period that had not yet ended. Whole milk obtained from treated cows was fed to calves on significantly more CON herds (38.4\% [CON] vs. $0.0 \%$ [ORG], $P<0.001)$, whereas whole milk obtained from untreated cows was fed to calves on more ORG herds $(25.3 \%[\mathrm{CON}]$ vs. $93.8 \%$ [ORG], $P<0.001)$. The majority of farms fed $\geq 3.78 \mathrm{~L}$ of colostrum to newborn calves $(80.0 \%$ [CON] vs. $63.4 \%$ [ORG], $P=0.29$ ).

Diagnosis of Johne's disease was more commonly reported on CON farms (48.5\%) compared with ORG farms $(25.0 \%$; $P=0.02)$. There was no significant association between recall of previous diagnosis of Salmonella or bovine viral diarrhea and herd type $(P>0.11)$. The use of coliform mastitis vaccines was more common on CON (47.5\%) compared with ORG dairy farms (15.6\%; $P=0.001)$.

\section{Antimicrobial Usage}

Records and recommendations for antibiotic use. Antibiotic treatment of both lactating and nonlactating cows was recorded on significantly more CON herds (Table 4). Likewise, reliance on veterinarian recommendations for antibiotic use, dosage, and withdrawal time was more common on CON herds (Table 4). Reliance on personal experience for recommendations for antibiotic use, dosage, and withdrawal time was cited by a high percentage of farmers on both ORG and CON herds. Advice obtained from other farmers for antibiotic withdrawal time was utilized by a low percentage of farmers on both CON and ORG herds. The product label was more frequently chosen as a source of withdrawal time information on CON, compared with ORG, herds. Recommendations obtained from other farmers for antibiotic use and dosage were more frequently cited by ORG farmers than on CON farmers. Antibiotic treatments of calves and heifers were recorded on approximately one-third of farms, regardless of herd type.

General antibiotic usage. Based on recall of the previous $60 \mathrm{~d}$, there was a significant association between the percentage of calves, bred heifers, and adult cows that received at least one antibiotic dose in the past $60 \mathrm{~d}$ and herd type (Table 5). One to ten percent of cows received at least one dose of antibiotics on the majority of CON herds, whereas no cows received antibiotics on the majority of ORG herds. More use of all antibiotics included in the survey was reported on CON herds compared with ORG herds (Table 6). 
Table 4. Antibiotic recommendations by herd type for conventional $(n=99)$ and organic $(n=32)$ dairy herds.

\begin{tabular}{|c|c|c|c|c|c|}
\hline & \multicolumn{2}{|c|}{ Conventional } & \multicolumn{2}{|c|}{ Organic } & $P$ \\
\hline Lactating cows & 71 & (71.7) & 6 & (18.8) & $<0.001$ \\
\hline Nonlactating cows & 58 & $(58.6)$ & 7 & $(21.9)$ & $<0.001$ \\
\hline Calves and heifers & 36 & $(36.4)$ & 11 & $(34.4)$ & $\mathrm{NS}^{2}$ \\
\hline \multicolumn{6}{|c|}{ Recommendations for antibiotic use from } \\
\hline Personal experience & 75 & $(75.8)$ & 27 & $(84.4)$ & NS \\
\hline Product label & 39 & $(39.4)$ & 10 & (31.3) & NS \\
\hline Other farmers & 27 & $(27.3)$ & 22 & $(68.8)$ & $<0.001$ \\
\hline \multicolumn{6}{|c|}{ Recommendations for antibiotic dosage from } \\
\hline Veterinarian & 96 & $(97.0)$ & 22 & $(68.8)$ & $<0.001$ \\
\hline Pharmaceutical representative & 8 & $(8.08)$ & 3 & $(9.4)$ & NS \\
\hline Personal experience & 65 & $(65.7)$ & 25 & (78.1) & NS \\
\hline Pharmaceutical representative & 4 & $(4.0)$ & 0 & $(0.0)$ & NS \\
\hline Personal experience & 54 & $(54.6)$ & 8 & $(25.0)$ & $<0.01$ \\
\hline Product label & 66 & $(66.7)$ & 4 & (12.5) & $<0.001$ \\
\hline Other farmers & 9 & $(9.1)$ & 5 & $(15.6)$ & NS \\
\hline
\end{tabular}

${ }^{1}$ Column totals within herd type can exceed number of enrolled herds because options were not exclusive choices.

${ }^{2} \mathrm{NS}=P>0.15$.

Antibiotics were used to treat dairy cattle on 15 ORG herds $(50 \%)$. Of the 15 herds using antibiotics, 14 (93.3\%) reported that they separated dairy cattle that received antibiotics from the rest of the ORG herd. The term "separated" referred to selling the animal or moving her to a location that did not allow physical contact with the rest of the ORG herd. The separation was permanent for $13(92.9 \%)$ of the 14 herds. Treated animals were used for ORG milk production after a withdrawal period had passed on 3 ORG farms (20\%). However, no animals previously treated with antibiotics were sold for ORG meat production.

Antibiotic usage in replacement animals. Antibiotics were used to treat respiratory disease and diarrhea in calves on significantly more CON herds compared with ORG herds (Table 7). The use of milk replacer containing antibiotics was reported on nearly half of the CON herds (49.5\%) compared with only one ORG herd $(3.1 \%)(P<0.001)$. There was no difference in the use of calf starter based on herd type (87.9\% [CON], 78.2\% [ORG], $P=0.14$ ) There was no significant association between herd type and the use of calf starter without antibiotics $(63.6 \%$ [CON], 68.8\% [ORG]; $P=$ $0.60)$, or use of calf starter with antibiotics $(24.3 \%$ [CON], 9.4\% [ORG], $P=0.07)$. Oxytetracycline (46.5\%) and neomycin $(42.4 \%)$ were the antibiotics most commonly reported used in milk replacers or calf starters on CON herds. The use of medications other than coccidiostats and ionophores in the feed or water of weaned calves and heifers was reported only by CON farmers (17.3\%; $P=0.01$ ), but only $4.0 \%$ of the farmers reported using these medications continuously. Chlortetracycline or another antibiotic was used as a medication in

Table 5. Use of antibiotics in animals on organic and conventional dairy herds in the $60 \mathrm{~d}$ preceding the interview. ${ }^{1}$

\begin{tabular}{|c|c|c|c|c|c|c|}
\hline \multirow{2}{*}{$\begin{array}{l}\text { Percent of herd } \\
\text { receiving at least } \\
1 \text { dose of antibiotics }\end{array}$} & \multicolumn{2}{|c|}{ Heifer calves ${ }^{1}$} & \multicolumn{2}{|c|}{ Bred heifers } & \multicolumn{2}{|c|}{ Adult cows ${ }^{1}$} \\
\hline & Conventional & Organic & Conventional & Organic & Conventional & Organic \\
\hline Zero & $25.3 \%$ & $78.1 \%$ & $82.8 \%$ & $0.0 \%$ & $5.1 \%$ & $90.6 \%$ \\
\hline $1-10 \%$ & $57.6 \%$ & $21.9 \%$ & $17.2 \%$ & $0.0 \%$ & $84.9 \%$ & $9.4 \%$ \\
\hline $11-25 \%$ & $10.1 \%$ & $0.0 \%$ & $0.0 \%$ & $0.0 \%$ & $9.1 \%$ & $0.0 \%$ \\
\hline$>25 \%$ & $7.0 \%$ & $0.0 \%$ & $0.0 \%$ & $0.0 \%$ & $0.9 \%$ & $0.0 \%$ \\
\hline
\end{tabular}

${ }^{1}$ Herd type was significantly associated with percentage of herd receiving antibiotics, $P<0.001$. 
Table 6. Types of antibiotics reported used in previous $60 \mathrm{~d}$ by organic and conventional dairy herds.

\begin{tabular}{llll}
\hline Antibiotic & Conventional & Organic & $P$ \\
\hline Penicillin type & $85.9 \%$ & $6.5 \%$ & $<0.001$ \\
Cephalosporin type & 77.85 & $9.7 \%$ & $<0.001$ \\
Tetracycline type & $41.4 \%$ & $3.2 \%$ & $<0.001$ \\
Sulfonamides & $27.3 \%$ & $0.0 \%$ & $<0.001$ \\
Florfenicol & $26.3 \%$ & $6.5 \%$ & $<0.05$ \\
Other antibiotics & $37.4 \%$ & $9.7 \%$ & $<0.01$ \\
\hline
\end{tabular}

the feed or water of weaned calves and heifers on $10.1 \%$ of CON herds.

Coccidiostats and ionophores. Use of decoquinate in rations of both preweaned calves $(60.6 \%$ [CON], $12.5 \%$ [ORG], $P<0.001)$, and weaned calves $(24.3 \%$ [CON], 3.1\% [ORG], $P=0.004$ ) was reported in more CON herds compared with ORG herds. Similarly, more CON herds reported the use of lasalocid to feed preweaned calves $(39.4 \%$ [CON], 3.1\% [ORG], $P<$ 0.001). There was no significant difference between CON and ORG herds for use of amprolium in preweaned calves $(10.1 \%$ [CON], 3.1\% [ORG], $P=0.22)$, or the use of other coccidiostats and ionophores in weaned calves (4.0\% [CON], 6.3\% [ORG], $P=0.60$ ). The use of coccidiostats and ionophores in bred heifers was not reported for ORG herds. Monensin $(22.2 \% ; P=0.002)$ and decoquinate $(5.05 \% ; P>0.11)$ were reported to be used on CON herds. Monensin was not used on any ORG herds but was used in weaned calves on $25.3 \%$ of CON herds $(P=0.001)$ and in preweaned calves on $9.1 \%$ of $\mathrm{CON}$ herds $(P>0.11)$.

Antibiotic usage in adult cows. Respiratory disease, mastitis, metritis or retained placenta, and foot
Table 8. Use of systemic antibiotics to treat selected diseases in adult cows.

\begin{tabular}{llcl}
\hline Disease & Conventional & Organic & $P$ \\
\hline Respiratory disease & $97.0 \%$ & $12.5 \%$ & $<0.01$ \\
Mastitis & $79.8 \%$ & $0.0 \%$ & $<0.001$ \\
Metritis or retained placenta & $79.8 \%$ & $3.1 \%$ & $<0.001$ \\
Foot problems & $82.8 \%$ & $6.3 \%$ & $<0.001$ \\
\hline
\end{tabular}

problems were treated more commonly with systemic antibiotics on CON herds compared with ORG herds (Table 8).

Ceftiofur was used in cows to treat respiratory disease, retained placenta or metritis, and foot problems on some ORG dairies (Table 9). More CON farmers reported the use of ceftiofur, tetracycline, penicillin, ampicillin, and sulfonamides to treat respiratory disease in cows compared with ORG farmers $(P<0.004)$, yet overall use of many of these antibiotics was relatively low (Table 9). There was no significant difference between herd types for use of florfenicol, tilmicosin, and other antibiotics for respiratory disease in cows because of the low use of these antibiotics in CON herds and the absence of use in ORG herds $(P>0.07)$. The use of systemic antibiotics to treat mastitis was not reported in ORG herds, but a variety of medications were reported to treat mastitis in CON herds, and additional products in the "other" category were reported in about one-fourth of CON herds $(P<0.007)$ (Table 9). There was no significant difference between herd type for systemic use of ceftiofur, sulfonamides, and erythromycin for mastitis in cows due to the low use of these antibiotics in CON herds and absence of use in ORG herds $(P$ $>0.11$ ). The use of ceftiofur to treat retained placenta

Table 7. Antibiotic usage in calves for conventional $(n=99)$ and organic $(n=32)$ dairy herds.

\begin{tabular}{|c|c|c|c|c|c|c|c|c|c|c|}
\hline \multirow[b]{3}{*}{ Antibiotic } & \multicolumn{5}{|c|}{ Respiratory disease } & \multicolumn{5}{|c|}{ Calf diarrhea } \\
\hline & \multicolumn{2}{|c|}{ Conventional } & \multicolumn{2}{|c|}{ Organic } & \multirow[b]{2}{*}{$P$} & \multicolumn{2}{|c|}{ Conventional } & \multicolumn{2}{|c|}{ Organic } & \multirow[b]{2}{*}{$P$} \\
\hline & $\mathrm{N}$ & $(\%)$ & $\mathrm{N}$ & $(\%)$ & & $\mathrm{N}$ & $(\%)$ & $\mathrm{N}$ & $(\%)$ & \\
\hline Use antibiotics to & 96 & $(97.0)$ & 11 & $(34.4)$ & $<0.001$ & 78 & $(78.8)$ & 7 & (21.9) & $<0.001$ \\
\hline Ceftiofur $^{1}$ & 37 & $(37.4)$ & 0 & $(0.0)$ & $<0.001$ & 11 & (11.1) & 0 & $(0.0)$ & 0.06 \\
\hline Tetracyclines $^{1}$ & 30 & $(30.3)$ & 1 & $3.1)$ & $<0.01$ & 21 & $(21.2)$ & 0 & $(0.0)$ & $<0.01$ \\
\hline Penicillin ${ }^{1}$ & 36 & $(36.4)$ & 5 & (15.6) & $<0.05$ & 9 & $(9.1)$ & 9 & $(9.4)$ & $\mathrm{NS}^{2}$ \\
\hline Ampicillin $^{1}$ & 8 & $(8.1)$ & 0 & $(0.0)$ & NS & & & & & \\
\hline Lincomysin-spectinomycin ${ }^{3}$ & 4 & $(4.0)$ & 1 & $(3.1)$ & NS & & & & & \\
\hline Tilmicosin 1 & 45 & $(45.5)$ & 3 & $(9.4)$ & $<0.01$ & & & & & \\
\hline Florfenicol $^{1}$ & 36 & $(36.4)$ & 2 & (6.3) & 0.001 & 13 & $(13.1)$ & 1 & $(3.1)$ & 0.11 \\
\hline Gentamycin $^{3}$ & 2 & $(2.0)$ & 0 & $(0.0)$ & NS & & & & & \\
\hline Trimethoprim-sulfa $^{3}$ & & & & & & 26 & $(26.3)$ & 1 & (3.1) & $<0.01$ \\
\hline Spectinomycin $^{3}$ & & & & & & 11 & $(11.1)$ & 0 & $(0.0)$ & 0.06 \\
\hline Enrofloxacin ${ }^{3}$ & 3 & $(3.0)$ & 0 & $(0.0)$ & NS & & & & & \\
\hline Other & 16 & $(16.2)$ & 2 & $(6.3)$ & NS & 22 & $(22.1)$ & 2 & (6.3) & $<0.05$ \\
\hline
\end{tabular}

${ }^{1}$ Antibiotic specifically mentioned in question.

${ }^{2} \mathrm{NS}=P>0.15$.

${ }^{3}$ Antibiotic volunteered by producers in the "other" category. 
Table 9. Antibiotic usage in adult cows in conventional $(\mathrm{n}=99)$ and organic $(\mathrm{n}=32)$ herds for selected ailments (percent). ${ }^{1,2}$

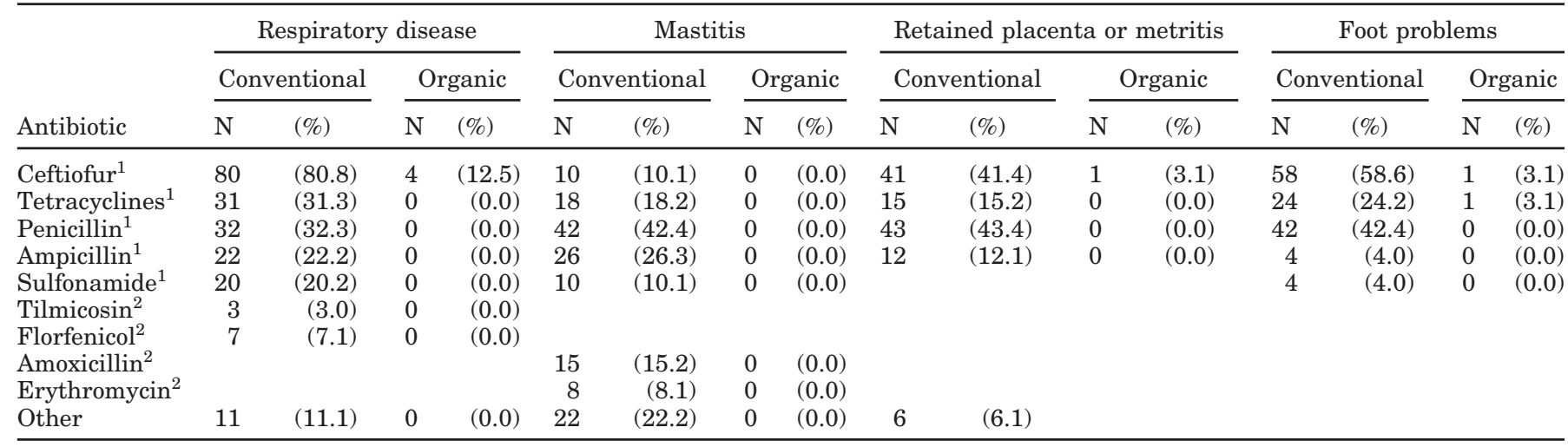

${ }^{1}$ Antibiotic specifically mentioned in question.

${ }^{2}$ Antibiotic volunteered by producers in the "other" category.

or metritis was reported in one ORG dairy, whereas ceftiofur, tetracycline, penicillin, and ampicillin were reported for treatment of retained placenta or metritis for cows in 12 to $43 \%$ of CON herds $(P<0.04)$ (Table 9 ). The use of systemic tetracycline and ceftiofur to treat foot problems in cows was reported in a single ORG herd compared with the use of ceftiofur, tetracycline, and penicillin to treat foot problems of cows in 24 to $59 \%$ of CON herds $(P<0.008)$ (Table 9$)$.

The use of antibiotics in footbaths (on regular schedule) to control or treat lameness was reported in 16 CON $(16.2 \%)$ and three $(9.4 \%)$ ORG herds $(P=0.34)$, whereas the continuous use of antibiotics in footbaths was reported in $14(14.2 \%) \mathrm{CON}$ and one (3.1\%) ORG herds $(P=0.09)$. No ORG herds reported the use of tetracycline $(P=0.02)$ and lincomycin $(P=0.06)$ in footbaths, but these products were used in $15(15.2 \%)$ and $11(11.1 \%)$ CON herds, respectively. Five (5.1\%) CON and three (9.4\%) ORG herds utilized antibiotics other than lincomycin and tetracycline in footbaths $(P=0.37)$.

There was a significant association between herd type for use of intramammary dry cow therapy $(P<0.001)$. Intramammary infusion of dry cow treatment was used in $97 \mathrm{CON}(98.0 \%)$ but only two ORG (6.3\%) herds. The preparation reported by the two ORG herds was a nonantimicrobial preparation. No use of intramammary dry cow treatments was reported by 30 ORG $(93.8 \%)$ and by just two $(2.0 \%)$ CON farmers.

\section{DISCUSSION}

Herds enrolled in this study were slightly larger and more productive compared with individual state averages (Table 1). The average herd size and rolling herd average reported by USDA in 2001 were 83 cows, 7794 kg (Wisconsin); 93 cows, 7950 kg (New York); 92 cows,
$8765 \mathrm{~kg}$ (Michigan); and 67 cows, $7837 \mathrm{~kg}$ (Minnesota) (USDA, 2001). The larger herd size we observed is probably a result of stratified herd selection and eligibility requirements that limited enrollment of herds with $<30$ cows.

This study was not designed to characterize the typical ORG or CON dairy herd, but data from this study did demonstrate a number of similarities and differences based on herd type. Organic herds were smaller and produced less milk than CON herds, leading us to question the comparability of antibiotic usage based on herd type. Results of the Cochran-Mantel-Haenszel test indicated that usage of specified antibiotics was associated with herd type and was not confounded by herd size. We were unable to perform direct comparisons of other management characteristics within herd size strata because of a limited number of large ORG dairy farms enrolled in this study. It is likely that a number of the management differences we noted based on herd type were strongly related to herd size. Most CON herds housed lactating cows in free stalls and milked in a parlor, whereas most ORG herds housed and milked lactating cows in tie stalls. The maternity area was separate from the housing of lactating cows for more CON herds compared with ORG herds, probably because more ORG herds used stall barns for housing adult cows. Many larger dairy farms have had the opportunity to build modern free-stall facilities as their herds expanded, but many smaller dairy herds (both ORG and CON) are housed in older, more traditional facilities. For some smaller dairy herds, the decision to adopt an ORG production system is perceived as a way to increase the value of their product without increasing herd size.

Management differences do exist between $\mathrm{CON}$ and ORG herds. Several practices highly adopted by ORG herds (such as housing preweaned calves in an individ- 
ual area and the use of individual water bowls for both milking and dry cows) could reduce the spread of disease. Conversely, the inability to use antimicrobials for prophylactic (dry cow therapy) and therapeutic purposes for mastitis could lead to an increase in chronic udder infections, increased SCC, and decreased milk quality on ORG farms.

Nutritional management was associated with herd type and is a possible explanation for the higher milk yield observed in CON dairy herds. Significantly more CON dairies fed cows a TMR, as well as a transition ration, and anionic salts to close-up cows. As expected, ORG herds used significantly less purchased feeds or feeds obtained from off-farm sources. The use of purchased feeds is limited for ORG dairy herds because feed must be raised organically for at least $3 \mathrm{yr}$. The only purchased feedstuffs that were used by ORG herds were whole soybeans and soybean meal. Organically raised soybeans are becoming increasingly available to support the organic farming industry.

More ORG herds used individual automatic water bowls for milking and dry cows compared with CON herds, associated with the type of housing. Shared water sources may be a potential source to spread disease among herdmates. Organic herds are required to have access to the outdoors, which probably explains the higher use of surface water for both milking cows and dry cows among ORG herds.

This study has several limitations. Most of the ORG herds were recruited by personal contact based upon proximity to universities. In most states, the enrollment process for ORG herds emulated a census, as virtually all identified ORG herds were invited to enroll. Some bias is introduced in virtually all studies that use commercial dairy herds because of the possibility that volunteer herds differ from nonresponders. The accuracy of reported antibiotic usage was not verifiable. Several dairy producers relied on memory to recall the amount and type of antibiotics, whereas others had comprehensive treatment records entered into a computer program. More CON herds recorded treatments of both lactating and nonlactating cows, but ORG herds reported significantly lower antibiotic usage. The percentage of ORG herds that did report recording treatments was similar to the percentage of herds that used antibiotics.

The potential for exposure of preweaned calves to antibiotics was higher on CON compared with ORG dairy farms. More CON dairies fed whole milk from cows that had received antibiotics and used milk replacer containing antibiotics. Similarly, few ORG dairies used coccidiostats and ionophores. These management differences are expected given the respective goals of ORG and CON herd management. Some manage- ment characteristics of farms were similar. The quantity of colostrum fed to newborn calves and the number of herds where cattle had been diagnosed with Salmonella and BVD did not vary based on herd type.

During the period of this study, there was no national standard for organic food production. Whereas each certifying organization could have differences in rules for their producers, the rules appeared to be largely similar. The current ORG standards were introduced after data collection for this study was completed; however, almost all ORG herds already appeared to be in compliance with the standards before their implementation. The current ORG standards state that producers of organic livestock must not withhold medical treatment from a sick animal in order to preserve its organic status. Livestock treated with a prohibited substance are required to be identified and removed from ORG production channels. As expected, lower percentages of animals were treated with antibiotics in ORG versus CON dairies. Organic farms are allowed to use antibiotics in ill adult cows if the animal and her products (milk) are removed from organic marketing channels. No ORG herds used antibiotics to treat mastitis; however, several ORG herds did report treating respiratory disease in cows with antibiotics. When ORG dairies did use antibiotics in cows, ceftiofur was the most commonly reported drug. During the time of our study, some organic certifying organizations allowed milk to be sold from cows treated with antibiotics after an extended withdrawal period had passed. Three ORG herds did report selling ORG milk from cows that had been treated with antibiotics, and one herd did not permanently separate animals that had received antibiotics from the rest of the herd. Current organic standards do not allow use of antibiotics for use in dairy animals producing a product sold as organic.

During the period of this study, about one-third of the ORG herds reported the use of antibiotics to treat ill calves. For ORG herds that did choose to use antibiotics, penicillin was the most commonly selected antibiotic used to treat calf diarrhea and respiratory disease. The current ORG standards specify that, during the transition to ORG status, dairy animals must be under ORG management for a full year before milk production is considered organic. After a herd has been converted to ORG status, all animals must be under ORG management from the last third of gestation.

Antibiotic injection practices have been previously reported for U.S. dairy herds (National Animal Health Monitoring System, 1997). Dairy producers $(\mathrm{n}=1219)$ from 20 states voluntarily responded to a questionnaire that addressed antibiotic injection practices employed during the past year. Of surveyed farms, 94 and $43 \%$ of farms reported that at least one antibiotic injection 
had been administered in the past year to at least $1 \%$ and $10 \%$ of all milk cows, respectively (National Animal Health Monitoring System, 1997). Similarly, our study found that $95 \%$ of farms reported that at least one antibiotic injection was administered in the previous 2 mo to at least $1 \%$ of all milk cows. This study confirms that a very low percentage of herds do not treat cows with antibiotics. However, our study found that fewer farms $(10 \%)$ reported that at least one antibiotic injection was administered in the previous 2 mo to at least $10 \%$ of all milk cows. These herds were managed conventionally.

McEwen et al. (1991) estimated usage of selected antibiotics based on mail survey results of Canadian dairy herds that had experienced antibiotic residue violations and paired control farms. Systemic antibiotics were administered to 1.3 to 1.6 cows per month (McEwen et al., 1991). Our study found that 84 of 99 CON herds treated 1 to $10 \%$ of adult cows with at least one antibiotic injection or oral dose of antibiotics in the previous 2 mo. These results are quite similar, given that the herd size of the Canadian herds was 50 (case herds) and 38 (control herds) cows. These results suggest that antibiotic usage of our study population was similar to the Canadian farm study population.

The use of intramammary dry cow treatment was highly adopted by CON dairy farms enrolled in this study. A study of 201 dairy herds in The Netherlands found that $82.8 \%$ of herds used dry cow treatment on all cows (Barkema et al., 1998). Current organic standards prohibit the use of dry cow therapy containing antibiotics, but antibiotic-free preparations are allowed.

An extensive study on drug use in Holstein calves ( $\mathrm{n}=$ 104 herds) located in Ontario was conducted between October 1980 and July 1983 (Waltner-Toews et al., 1986). Treatment days were calculated as the number of calves treated multiplied by the number of days each calf received treatment. The percent of treatment days in 4977 calves was reported for: chloramphenicol (32.0\%), tetracycline (17.1\%), commercial mixtures (13.7\%), penicillin (13.3\%), trimethoprin-sulfonamide (8.1\%), sulfonamides (4.9\%), and other antibiotics (10.9\%). The availability and legality of antibiotics has changed since that study was conducted. The use of many antibiotics (trimethoprin-sulfa, tetracycline, penicillin, and other antibiotics) remains common for treatment of calf ailments. Several additional products (tilmicosin, florfenicol, ceftiofur, and enrofloxacin) have been developed in recent years. Enrofloxacin is approved for use in the treatment of respiratory disease in cattle. However, it is not approved for use in veal calves or cattle intended for dairy production. In the Canadian study farms, $76.9 \%$ fed milk replacer or calf starter that did not contain antibiotics, whereas $19.2 \%$ used tetracycline and 3.9\% used another antibiotic in milk replacer or calf starter (Waltner-Toews et al., 1986). Although similar drugs were used to treat calf ailments, herds enrolled in this study used considerably more antibiotics in calf starter and milk replacer compared with the Ontario dairy farms.

The results of this study show that, as expected, CON dairy farms reported significantly more use of antibiotics to treat specific ailments in both calves and cows when compared with ORG dairy farms. Most antibiotics used were approved for use in dairy cattle and appropriately used; however, a small number of herds did report the use of antibiotics that are prohibited for use in dairy. Antibiotic usage data are limited and hard to describe accurately on dairy farms. Disclosure of the data is reliant on producers' records and/or memory. In the future, more research needs to be conducted to quantify antimicrobial usage on dairy farms. As the regulations for ORG herds become more defined, further research will be needed to account for the management changes inherent in tighter regulations.

\section{CONCLUSION}

Management differences existed between CON and ORG dairy herds in several areas. Organic herds were smaller and produced less milk compared with CON dairies. Organic dairies were more likely than CON dairies to house lactating cows in tie stalls and house preweaned calves in an individual area. More CON dairies than ORG dairies used purchased feeds and feeds obtained from off-farm sources. This study identified several characteristics of ORG herds that could reduce the need for antibiotics. However, the inability to treat mastitis and use dry cow therapy could result in higher SCC values. Reported antibiotic usage on this study was relatively low for CON dairy herds, but milk replacer containing antibiotics was used by $49.5 \%$ of enrolled CON dairy herds. Antibiotic use was slightly higher in heifer calves as compared to cows. Antibiotic use was lowest in bred heifers. Most ORG dairy farms were in compliance with current organic regulations even though the current standards had not yet been implemented.

\section{ACKNOWLEDGMENT}

The authors thank RoseAnn Miller for technical assistance with data management.

\section{REFERENCES}

Barkema, H. W., Y. H. Schukken, T. J. G. M. Lam, M. L. Beiboer, G. Benedictus, and A. Brand. 1998. Management practices associated with low, medium, and high somatic cell counts in bulk milk. J. Dairy Sci. 81:1917-1927. 
Green, C. 2000. U. S. organic agriculture gaining ground. Economic Research Service/USDA. Agriculture Outlook. 9-14. http:/ www.ers.usda.gov/epubs/pdf/agout/apr2000/ao270d.pdf. Accessed Feb. 2003.

Hoeben, D., C. Burvenich, and R. Heyneman. 1998. Antibiotics commonly used to treat mastitis and respiratory burst of bovine polymorphonuclear leukocytes. J. Dairy Sci. 81:403-410.

McEwen, S. A., A. H. Meek, and W. D Black. 1991. A dairy farm survey of antibiotic treatment practices, residue control methods and associations with inhibitors in milk. J. Food Prot. 54:454-459.

Mitchell, J. M., M. W. Griffiths, S. A. McEwen, W. B. McNab, and A. J. Yee. 1998. Antimicrobial drug residues in milk and meat: causes, concerns, prevalence, regulations, tests, and test performance. J. Food Prot. 61:742-756.

National Animal Health Monitoring System. 1997. Antibiotic injection practices on U.S. dairy operations. United States Department of Agriculture Animal and Plant Health Inspection Service. Online. Available: http://www.aphis.usda.gov/vs/ceah/cahm/ Dairy_Cattle/d96anti.htm. Accessed February 2003.

National Organic Program; Organic production and handling standards. October 2002. http://www.ams.usda.gov/nop/FactSheets/ ProdHandE.html. Accessed November 6, 2002.

SAS User's Guide: Statistics, Version 8 Edition. 1999. SAS Inst., Inc., Cary, NC.

Sundlof, S. F., J. B. Kaneene, and R. A. Miller. 1995. National survey on veterinarian drug use in lactating dairy cows. JAVMA 207:347-352.

United States Department of Agriculture's National Agricultural Statistics Service. http://www.usda.gov/nass/. Accessed December $5,2002$.

Waltner-Toews, D., S. W. Martin, and A. H. Meek. 1986. Calf-related drug use on Holstein dairy farms in southwestern Ontario. Can. Vet. J. 27:17-22 